\title{
Correction to: A multigenerational study on phenotypic consequences of the most common causal variant of HNF1A-MODY
}

\author{
Jarno L. T. Kettunen ${ }^{1,2,3,4}$ (D) Elina Rantala ${ }^{5}$ Om P. Dwivedi ${ }^{2}$ (D) - Bo Isomaa ${ }^{1}$ - Leena Sarelin ${ }^{1}$ • Paula Kokko ${ }^{1,2,4}$. \\ Liisa Hakaste ${ }^{1,2,3,4}$ (D) Päivi J. Miettinen ${ }^{6,7}$ (D) $\cdot$ Leif C. Groop ${ }^{2,8}$ (D) $\cdot$ Tiinamaija Tuomi ${ }^{1,2,3,4,8}$ (D)
}

Published online: 3 March 2022

(C) Springer-Verlag GmbH Germany, part of Springer Nature 2022

\section{Correction to: Diabetologia}

$$
\text { https://doi.org/10.1007/s00125-021-05631-z }
$$

The legend for Fig. 3 incorrectly stated 'the dashed grey lines represent sex-specific medians' but should have stated 'the dashed grey lines represent medians'. The original article has been corrected.

Publisher's note Springer Nature remains neutral with regard to jurisdictional claims in published maps and institutional affiliations.

The online version of the original article can be found at https://doi.org/ $10.1007 / \mathrm{s} 00125-021-05631-\mathrm{z}$

Tiinamaija Tuomi

tiinamaija.tuomi@hus.fi

1 Folkhälsan Research Center, Helsinki, Finland

2 Institute for Molecular Medicine Finland (FIMM), University of Helsinki, Helsinki, Finland

3 Department of Endocrinology, Abdominal Center, Helsinki University Hospital, Helsinki, Finland

4 Research Programs Unit, Clinical and Molecular Metabolism, University of Helsinki, Helsinki, Finland

5 Vantaa Healthcare Center, Vantaa, Finland

6 New Children's Hospital, Pediatric Research Center, University of Helsinki and Helsinki University Hospital, Helsinki, Finland

7 Research Programs Unit, Molecular Neurology, and Biomedicum Stem Cell Center, University of Helsinki, Helsinki, Finland

8 Lund University Diabetes Center, Department of Clinical Sciences Malmö, Lund University, Malmö, Sweden 